\title{
RELEVANSI NILAI SASTRA PADA LIRIK LAGU RIDWAN SAU DENGAN KONDISI SOSIAL BUDAYA MASYARAKAT KOTA MAKASSAR (SUATU PENDEKATAN STRUKTURAL GENETIK)
}

\begin{abstract}
Sarwinah
Abstrak

Penelitian ini bertujuan untuk menemukan jawaban atas fokus permasalahan yang telah dirumuskan yakni mendeskripsikan nilai sastra hideonik, nilai artistik, nilai kultural, nilai etis,moral, dan agama, serta nilai praktis yang terdapat pada lirik lagu Ridwan Sau, kondisi sosial budaya kota Makassar, ditinjau dari makna lagu Ridwan Saud dan relevansi nilai sastra pada lirik lagu Ridwan Sau dengan kondisi sosial budaya masyarakat Kota Makassar. Penelitian ini sebagai penelitian kualitatif, dengan pendekatan struktural genetik yang mempergunakan strategi berpikir fenomenologis yang lentur dan terbuka dari pencipta lagu daerah Makassar. Adapun lirik-lirik lagu yang digunakan sebagai objek penelitian ini adalah Julei Rikau, Tea Tonja, Burakne Tonja, Panngukrangi, Sarengku, Kakde Kapang Na Suruga, Harangmi, Larokong Tojengma Kapang, Naloko Nakku, I Kattemi Antu, Tea Lapanra Pinruang, dan Kere Tekneku. Pengumpulan data dengan teknik kaji dokumen. Analisis data dilakukan sejak awal peneliti mengumpulkan data, lalu mereduksi data kemudian menyajikan data, dan melakukan penelitian data dan penarikan kesimpulan. Selanjutnya diadakan teknik pemeriksaan keabsahan data. Hasil penelitian ini mendeskripsikan relevansi nilai sastra pada lirik lagu Ridwan Sau dengan kondisi sosial budaya masyarakat Kota Makassar. Yaitu antara nilai hideonik, nilai artistik, nilai cultural, nilai etis, dan nilai praktis dengan kondisi sosial budaya kota Makassar yang antara lain masih menganut ketat budaya Tau, budaya Sirik, budaya Pacce, budaya Panngalik, budaya Panngadakkang, dan budaya Agama (Batara). Budaya-budaya tersebut masih dianut sampai sekarang dan sudah menjadi kebiasaan dalam keseharian masyarakat Kota Makassar yang semuanya tercantum dan tergambar dalam lagulagu ciptaan Ridwan Sau.
\end{abstract}

\section{Kata Kunci: nilai sastra, lirik lagu Ridwan Sau, sosial budaya Makassar}

\begin{abstract}
This research aims to find answers to focus the issues that have been formulated to describe the value hideonik literary, artistic value, cultural values, ethical values, morals, and religion, as well as practical value contained in the lyrics of the song Ridwan Sau, socio-cultural city of Makassar, reviewed of the meaning of the song Ridwan Saud and the value relevance literature Ridwan Sau lyrics with social and cultural conditions of Makassar. This research was qualitative research with the genetic structural approach that used the phenomenology strategy openly from the outhor of Makassar song. The lyrics was used by the researcher was Julei Rikau, Tea Tonja, Burakne Tonja, Panngukrangi, Sarengku, Kakde Kapang Nasuruga, Harangmi, Larokong Tojengma Kapang, Naloko Nakku, I Kattemi Antu, Tea Lapanra Pinruang, and Kere Tekneku. The technique in collected, then taking reduction and presenting the data, and concluding. The next technique was validation. The research findings described The Relevance of Literature Value Toward the Lyrics of Ridwan Sau song with the condition of Social Culture of Makassar. It was the hedonic value, art value, cultural value, ethic value, and practical value with the social culture condition of Makassar community that submitted the Tau culture, Sirik culture, Pacce culture, Panngalik culture, Panngadakkang culture, and Religious (Batara) culture. Those culture still submit until now and became a habit in daily life of Makassar Community that quoted in Ridwan Sau song.
\end{abstract}

Key words: literature value, Lyrics of Ridwan Sau Song, Makassar Social Culture 


\section{Pendahuluan}

Karya sastra mempunyai kehidupan sosial humaniora yang luar biasa dan terdapat di dalam kebudayaan. Baik pengarang maupun pembaca dapat menyalurkan apresiasi kreatifnya melalui karya sastra. Kolaborasi pengalaman pengarang dan improvisasi terhadap topiktopik kehidupan menjadikan karyanya semakin hidup dan dinikmati oleh para pembaca sastra. Nilai-nilai sastra seperti nilai hedonik, nilai artistik, nilai kultural, nilai etis, dan nilai praktis yang terkandung dalam setiap bentuk karya sastra telah menggugah banyak orang untuk mencipta berbagai bentuk karya sastra. Para penikmat sastra juga dapat menerapkan hasil dari proses membacanya dengan menenggelamkan dirinya ke dalam karya sastra tersebut sehingga diperoleh gambaran maksud yang ingin disampaikan pengarang.(Sri Wahyuningtyas, 2011: 5).

Pendekatan struktural genetik dianggap sebagai satu-satunya pendekatan yang mampu merekonstruksikan pandangan dunia pengarang, mengoreksi pendekatan struktural otonom dengan memasukkan faktor genetik dalam memahami karya sastra. Genetik diartikan sebagai asal-usul karya sastra yang meliputi pengarang dan realita sejarah yang turut mendukung penciptaan karya sastra tersebut. Latar belakang sejarah, zaman, sosial masyarakat memiliki andil yang signifikan terhadap karya sastra baik dalam segi isi maupun bentuk.

Keberadaan pengarang dalam lingkungan sosial masyarakat tertentu, ikut mempengaruhi karya yang dibuatnya. Dengan demikian suatu masyarakat tertentu yang ditempati pengarang akan dengan sendirinya mempengaruhi jenis sastra tertentu yang dihasilkan pengarang. Hakikat struktural pada pendekatan ini terletak pada cara penelitian karya sastra dan hubungannya dengan sosial budaya.

Berangkat dari pendekatan struktural genetik penulis tertarik untuk mengkaji relevansi nilai sastra pada lirik lagu yang diciptakan Ridwan Sau dengan kondisi sosial budaya masyarakat Makassar . Ada hal menarik yang penulis lihat dari lirik-lirik lagu tersebut kerena banyak karya tersebut berlatar kehidupan budaya di Kota Makassar.

Karya-karya Ridwan Sau memiliki latar kenyataan yang cukup mantap. Kenyataan tersebut berasal dari hidupnya sendiri, lahir dan batin; kenyataan hidup atau kejadian orang-orang di sekitarnya; kenyataan masyarakat Sulawesi Selatan khususnya masyarakat suku Makassar yang berdomisili di daerah-daerah sekitar Kota Makassar seperti Gowa, Takalar, dan Jeneponto, dan akhirnya kenyataan sejarah. Beberapa karyanya cukup melankolis, bercerita tentang hubungan cinta kasih yang selalu dituntut untuk selalu abadi namun berakhir tidak sesuai dengan harapan. Adakalanya tematema seperti itu bercampur aduk dalam satu album lagu. Namun, relevansinya dengan kondisi sosial budaya masyarakat Makassar senantiasa mewarnai seluruh karyanya.

Ridwan Sau, sebagai sosok pemuda pencipta dan penyanyi lagu khususnya lagu daerah Makassar, fitur pemuda produktif. Di usianya yang masih muda dalam waktu kurang lebih tujuh tahun mampu menciptakan lagu sebanyak kurang lebih 50 lagu yang terdapat pada empat album pribadi dan dua album kompilasi, yang hampir keseluruhan lagu-lagu tersebut dinyanyikannya sendiri.

Hal itulah yang menarik bagi penulis untuk meneliti apakah ada dan bagaimanakah relevansi nilai satra pada lirik lagu Ridwan Sau dengan kondisi sosial budaya Makassar ( suatu pendekatan struktural genetik ). Di samping itu, penelitipeneliti yang terdahulu belum pernah meneliti relevansi nilai sastra pada lirik lagu Ridwan Sau dengan kondisi sosial budaya Makassar sehingga semakin memperkuat alasan untuk meneliti hal tersebut.

\section{TINJAUAN PUSTAKA}

Karya sastra yang baik senantiasa mengandung nilai (value). Nilai itu dikemas dalam wujud struktur karya sastra, yang secara implisit terdapat dalam alur, latar, 
tokoh, tema, dan amanat atau di dalam larik, kuplet, rima, dan irama. Nilai yang terkandung dalam karya sastra itu antara lain sebagai berikut:

1. Nilai hedonik (hedinic value), yaitu nilai yang dapat memberikan kesenangan secara langsung kepada pembaca;

2. Nilai artistik (artistic value), yaitu nilai yang dapat memanifestasikan suatu seni atau keterampilan dalam melakukan suatu pekerjaan;

3. Nilai kultural (cultural value), yaitu nilai yang dapat memberikan atau mengandung hubungan yang mendalam dengan suatu masyarakat, peradaban, atau kebudayaan;

4. Nilai etis, moral, agama (ethical, moral, religious value), yaitu nilai yang dapat memberikan atau memancarkan petuah atau ajaran yang berkaitan dengan etika, moral, atau agama;

5. Nilai praktis (pratical value), yaitu nilai yang mengandung hal-hal praktis yang dapat diterapkan dalam kehidupan nyata sehari-hari.

\section{Nilai-Nilai dalam Kebudayaan Makassar}

Dalam kebudayaan Makassar terdapat sejumlah nilai dan konsep yang sangat besar pengaruhnya dalam perilaku dan pergaulan sosial etnis Makassar.

a. Makna Nilai Tau 'Orang' dalam budaya Makassar

Untuk mengetahui Tau 'Orang' dalam budaya Makassar akan diuraikan bukti-bukti linguistik, khususnya metafora yang mengandung nilai tersebut. Wacana di bawah ini terdiri atas tiga metafora:

Antu nikanaya tau akrupa-rupai. Niak tau, tau tojeng. Niak tau poro tau Niak tau, akkanaji na tau.

Terjemahannya:

Manusia itu bermacam-macam. Ada manusia, benar-benar manusia. Ada manusia sekadar manusia. Ada manusia dikatakan manusia karena ia dapat berbicara.

\section{b. Makna Nilai Sirik 'Harga Diri}

Sirik sebagai sistem nilai budaya yang abstrak sangat sulit didefinisikan, karena ia hanya dapat dirasakan secara sempurna oleh penganut kebudayaan itu. Agar jelas dikemukakan terlebih dahulu beberapa contoh metafora yang mengandung nilai sirik.

Siri Paccea rikatte, kontu ballak ia benteng, ia patongko, ia todong jari rinring.

Terjemahannya:

'Harga diri dan kesetiakawanan bagi kita, ibarat rumah ia adalah tiang, ia atap, ia juga jadi dinding'.

\section{c. Makna Nilai Pacce ' Iba'}

Secara leksikal pacce berarti pedih, perih. Membantu orang tua jompo yang ditelantarkan oleh anaknya, membantu yatim piatu yang ditinggalkan ibu bapaknya, karena rasa iba yang menyentuh hati, paccei parukka 'iba' hati melihatnya. Hal yang mendorong seseorang melakukan sesuatu disebut pacce 'iba'.

\section{d. Makna Nilai Pangngalik 'perasaan} hormat'

Cense (1979) mencatat arti pangngalik dengan kata Schroom 'segan' kata ini berasal dari leksem schroom 'takut atau rasa hormat'. Contoh: Segenap penduduk di kampung itu segan kepada guru mengaji itu".

Kata turunan lainnya dari angngalik ialah sipangngaliki 'saling menghormati'. Ajaran ini merupakan salah satu dari wujud sipakatau 'saling menganggap manusia'. Dalam kehidupan orang Makassar sering terdengar ujaran: punna erokko nipangngaliki, pangngaliki rong taua ' jika ingin dihormati, hormatilah orang terlebih dahulu.

e. Makna nilai Pangngadakkang 'adat istiadat'

Pangngadakkang berasal dari kata adak 'adat' yang oleh Matthes diterjemahkan dengan gewoonten 'kebiasaan-kebiasaan'. Adat ialah himpunan kaidah-kaidah sosial yang sejak lama ada, merupakan tradisi dalam masyarakat yang bermaksud mengatur tata tertib masyarakat. 
III. Metode Penelitian

Penelitian ini menggunakan pendekatan kualitatif. Penentuan jenis penelitian ini disesuaikan dengan permasalahan, sifat. Dan tujuan penelitian. Dalam rangka mencapai tujuan, maka dipergunakan strategi berpikir fenomenologis yang lentur dan terbuka. Bentuk analisis menggunakan analisis secara induktif dengan meletakkan data penelitian bukan sebagai pembuktian, melainkan modal untuk memahami dan menyimpulkan fakta yang ada. Desain yang dimaksud tidak kaku sifatnya sehingga memberi peluang kepada peneliti untuk menyesuaikan diri dengan konteks yang ada. (Sutopo dalam Azis, 2011: 86).

Adapun judul-judul lirik lagu Ridwan Sau yang dijadikan sumber data dalam penelitian ini adalah bersumber dari teks lagu-lagu Ridwan Sau yaitu Julei Rikau, Tea Tonja, Bura'ne Tonja, Pangngurangi, Sarengku, Ka'de Kapang Nasuruga, Piadaki Adaka, Harangmi, Larokong Tojengma Kapang, Naloko Nakku, I Kattemi Antu, Tea Lapanra Pinruang, dan Kere Tekneku.

Pengumpulan data dilakukan dengan cara:

1. wawancara langsung dengan Ridwan Sau sebagai narasumber utama, dan tokoh-tokoh masyarakat yang dianggap mengetahui kondisi sosial budaya Makassar sejak dulu sampai sekarang ini.

2. Perekaman hal-hal yang dianggap penting sebagai sumber data penelitian

3. Pengamatan dan pencatatan terhadap hal yang telah diteliti

\section{HASIL PENELITIAN DAN PEMBAHASAN}

A. Nilai Sastra pada Lirik Lagu Ridwan Sau

Nilai Sastra yang terdapat pada lagu Ridwan Sau yaitu nilai hideonik, nilai artistik, nilai kultural, nilai etis, dan nilai praktis. Untuk lebih jelasnya diperhatikan uraian berikut ini.
1. Nilai hideonik

Nilai hideonik atau nilai kesenangan dan kebahagiaan dapat dilihat pada lirik lagu Julei Rikau berikut ini.

Kakdek nia parekanna

\section{Lassialle tallasatta}

Kaumi intang nyawaku

(Album

ke -2 Ridwan Sau: Julei Rikau)

Terjemahannya:

Andaikan ada suatu hal

Yang dapat membuat kita sejodoh

Kau kan kujadikan permata di hatiku

Nilai hideonik ini juga tergambar pada lirik lagu Tea Tonja berikut:

Tikring nia moncong mata

Battu paksisalkla apamo gauku sala

Numallangki-langki kamma

Ingka bolimi nakamma sarengku

Sannging salasa tallasakku

(Album ke-2 Ridwan Sau: Julei Rikau)

Terjemahannya:

Seandainya itu ada pekasi

Kenapa kita berpisah

Apa gerangan salahku

Sehingga engkau melupakanku

Namun demikian biarlah hidupku dililit kekecewaan

Nilai kesenangan dan kebahagiaan tergambar pula pada lirik lagu I Kattemi Antu berikut:

Kontu jamarro panngainta

Bulaeng erang nyawata

Apamo anjo takatte sabak

Niakku empo suruga

(Album ke-3 Ridwan Sau: Jojama Nakke)

Terjemahan:

Bagaikan zamrud kasih sayangmu

Bagaikan emas hatimu

Karena engkaulah

Aku bisa masuk surga

Pada lirik-lirik lagu di atas banyak mengandung nilai-nilai kesenangan dan kebahagiaan baik itu pertemuan dengan sang kekasih, kekaguman pada kecantikan seseorang, dan kebahagiaan menjalani kehidupan, serta untuk menyatakan kebaikan dan kasih sayang ibu.

2. Nilai artistik 
Lagu-lagu Ridwan Sau mengandung nilai artistik yang mengangkat citra kedaerahan masyarakat Makassar. Selain itu kata-kata yang digunakan dalam lirik-lirik lagu tersebut banyak mengandung nilai artistik yang diakhiri oleh fonem a, i, u, e, dan o. Kalimat-kalimat yang digunakan dalam lirik lagu tersebut banyak mengandung perumpamaan. Seperti tergambar pada lirik lagu Kere Tekneku berikut:

Kakde kapang na leko rapang kayu sitangke Kutippasami kurusuji

Natea ngerangi simpung

(Album ke-1 Ridwan Sau: Bidadari)

Terjemahan:

Andaikan pepohonan yang memiliki kayu seranting saja

Kuambil dan kupatahkan

Untuk mengirimkan hatiku padamu

Nilai artistik ini juga dapat dilihat pada lirik lagu Tea La Panra Pinruang bait ke tiga berikut:

Runtummi bulu ruayya

Sosara bawakaraeng

Panrakka nakke anne

Kutuli kamma mama

Latakkalupa ri allo bokoa nalakju cinta

(Album ke-3 Ridwan Sau: Jojama Nakke)

Terjemahan:

Ibaratnya dua gunung runtuh

Bawakaraeng sana akan longsor

Saya akan binasa seandainya perasaan ini Ingatanku ini tidak hilang padamu

Kulupakan hari akhir karena cintaku padamu

\section{Nilai kultural}

Lirik lagu Ridwan Sau banyak dipengaruhi dengan nilai kultural masyarakat Kota Makassar baik itu nilai kultural. Nilai kultural dapat dilihat pada lirik lagu Burakne Tonja berikut:

Ingka punna simpung-simpung tojengnga anne

Nacarita loko-loko tena rapangku

Tena tojeng ruanna batennu apparisi $2 x$

Ingka nakke andi burakne tonja

Aklampako pacce ammantangko sirik

(Album ke-2 Ridwan Sau: Julei Rikau)
Terjemahan:

Kalau aku benar-benar resah seperti ini

Dicerca sakit hati yang demikian

Tak ada duanya kurasakan sakitnya

Saya seorang lelaki

Aku masih punya harga diri

\section{Nilai moral}

Pada setiap lirik lagu Ridwan Sau ada pesan dan nilai moral yang dikandung dan ingin disampaikan pada pendengar dan penikmat lagu. Seperti yang tergambar pada lagu Harangmi berikut:

Kupattojeng loko tena balleanna

Kapang rapangna pakrisiku

Ilahi karaeng sare panngurangi

Inakke loko tojengnga

I Sau simpung tonji

Terjemahan:

Akupun terluka tidak ada obatnya

Seperti sakit hatiku tak ada duanya

Bersyukur Tuhan memberi ingatan kepadaku

Meskipun saya sakit

Saya sangat sakit

Bait lagu di atas menunjukkan bahwa seseorang yang telah mengalami sakit hati dan keputusasaan pada akhirnya harus mengembalikannya kepada Ilahi sang Pencipta.

5. Nilai praktis

Lirik lagu Ridwan Sau mengandung nilai-nilai praktis karena tercipta dari peristiwa keseharian yang dialami masyarakat Makassar maupun pengalaman sendiri yang dituangkan dalam lirik lagu. Seperti lirik lagu Sarengku berikut:

Allo banngi turung songokku

Anjappa timboro wara

Nakumminasa sarengku masunggua

Terjemahan

Siang malam bercucuran keringatku

Berjalan dari timur ke barat

Kuterima nasibku yang digariskan Tuhan

B. Nilai-Nilai dalam Kebudayaan Makassar

1. Budaya Tau 'Orang Budaya Tau 'Orang tampak pada kalimat lirik lagu Julei Rikau berikut ini 
Baji kuassengna lomponaka

Pangainu ri kalengku

Keremi laku padongko

Panngranuang ri atinnu

Alle asseng mami asseng mami

Rinyawanu

Lompotonji pangainku

Kakdek nia parekanna

Lassialle tallasatta

Kaumi intang nyawaku

Cinna memang sekre ni julu

Numanngai kupattojengna

Ingka iya julei rikau

Kirurungan kisingai

Lanri nia nasampangku

Tuli battu dinging-dingingku

Anrerai sarengta sayang

Ingka iya lonna nakamma

Battu rikau tommami

Asseng mami empoangku

(Album ke-2 Ridwan Sau: Julei Rikau)

Kata kuassengna berarti kutahu atau orang yang memberitahu. Pada baris kedua kalimat pangainu ri kalengku yang berarti cintamu pada diriku. Mu pada kata pangainu berarti orang yang dianggap sudah akrab terhadap diri sendiri dan ku pada kalengku berarti orang yaitu diri sendiri.

Pada bait kedua dan ketiga terdapat kata tallasatta dan sarengta yang berarti kehidupan kita dan nasib kita. Kata kita sering digunakan masyarakat Makassar yang berarti penghormatan buat diri sendiri dan orang lain. Pada bait selanjutnya terdapat kata rikau yang berarti orang namun karena dianggap sudah akrab sehingga disebut kamu.

Budaya tau juga banyak tergambar pada lagu Kere Tekneku berikut ini:

Sarengku...

Lekba ni tantuangna

Laku erang keremi

Pakrisi tena sanggana

O... daeng

Pallakna nyawata daeng
Lompo pakmarisita

Takngurangi biasata

Laku erang keremi

Kere pakrimpunganna

Pia lokokku sangga susaku

Nakulle tekne nyawaku

Kakde kapang na leko rapang kayu sitangke

Kutippasami kurusuji

Natea ngerangi simpung

(Album ke-1 Ridwan Sau: Bidadari)

Pada kata sarengku, susaku, lokokku, nyawaku yang semuanya berakhiran ku yang berarti aku orang yang menyatakan diri sendiri. Selain itu terdapat kata daeng yang dalam bahasa Makassar berarti orang yang dituakan atau lebih tua dari usia subyek kalimat. Terdapat pula kata nyawata, pakmarisita, dan biasata yang diakhiri dengan kata ta yang dalam bahasa Makassar berarti sebutan terhormat bagi orang yang dikenal atau disegani

2. Nilai Budaya Sirik 'Harga Diri'

Nilai Sirik terdapat pada lagu Burakne Tonja berikut ini:

Ingka punna simpung-simpung tojengnga anne

Nacarita loko-loko tena rapangku $2 x$

Tena tojeng ruanna batennu apparisi $2 x$

Ingka nakke andi burakne tonja

Aklampako pacce ammantangko sirik $2 x$

Manna nulampa rinakke andile

Manna nuboko pangai ri kodong

Manna taksirurungan tallasatta

Tenaja nataena ero ri nakke

Gassing nukana kalengnu andile

Tunggalako masaru kanang-kanang

Bara nukana kalengnu baule

Tena ruannu sayang salako andi

Jaiji bau

Jai rapangnu

Teako andi teako sayang pacapa dudu

Barang tenaja kutuli salasa 
Tenaja kapang

Barang nabuntu-buntulu tonja tekne Manna ta kau

(Album ke-2 Ridwan Sau: Julei Rikau)

Harangmi

Niakmi anne ri nyawana

Kutakngurangi ri jarrena janjinku

Aule ...tana assengnga

Pakrisi ri mabokoku

Tenamo anne parekanna

Sileporang sitikriang pangai

Nyawanu na ri nyawaku

Sekre pakrisi ni julu

Sallang nakkukku sallang pakngaiku

Tuli rikau tonji njaji ri erotta

Harangmi..Tena parekanna

(Album ke-4 Ridwan Sau: Harangmi)

Pada lagu Burakne Tonja terdapat

kata ammantangko sirik merupakan kata yang biasa digunakan masyarakat Makassar yang memiliki harga diri.

Secara keseluruhan kata-kata dari lagu Burakne Tonja di atas menggambarkan budaya sirik yang dianut masyarakat Makassar. Bila seseorang merasa dipermalukan oleh orang lain terlebih lagi oleh seorang wanita maka mereka akan bertindak untuk mempertahankan siriknya.

Pada lagu kedua Harangmi merupakan gambaran seorang pria yang tersakiti oleh kekasihnya sehingga ia mengharamkan lagi hatinya pada wanita tersebut. Ini biasa dilakukan oleh masyarakat Makassar yang merasa harga dirinya terinjak-injak oleh seseorang sehingga berbuat demikian.

\section{Nilai Budaya Pacce 'Iba'}

Nilai Pacce dalam masyarakat

Makassar bukan karena belas kasihan , akan tetapi rasa yang paling dalam untuk saling menyempurnakan niat baik keluarga kedua belah pihak. Seperti halnya pacce yang digambarkan pada lagu berikut:

Kakde Kapang Na Suruga
...Tena rapangku ri lino

Kapamaiknu tong mami

Pacceku ri sukku lompoa

Kupadallekang ri kau

Tuli kupatanro sayang

Lompo panrannuangku tanasai sileporang

Takuasseng empoangku tuni

kalanreangKakde kapang na suruga mate

taria jalatta

Kubunomi kalengku lanri pakrisikku

Lekba mami kapang parekna anne linoa

Katte kamasea sayang

Tuli ni pare konteng

Kuasseng tuna kalengku

Kapakmaikku tong mami

Pacceku sukku lompo

Kupadallekang ri kau

Tuli kupatanro sayang

(Album ke-1 Ridwa Sau: Bidadari)

Larokong Tojengma Kapang

...Punna tena memang tommo cinnanu ri nakke

Kukarannuang lansaleori nakkukku ri kau

Bolimi kamma nakuerang

Simpung rera susa loko pacce nyawaku

Sayang......

Ngapa tanu alle tommo anne nyawaku

Nasukku mange pakmarrisinu

Rinakke kodong

Nalekba mange pakrisiknu...sayang

(Album ke-3 Ridwan Sau: Jojama Nakke)

Tea Tonja

Pacce tojengngi paeng

Empoanna kamasea lani kanyame

kapangaian

Tekneji puru kurampe

Nupare panyaleori

Paikji paleng kalebakkanna

(Album ke 1 Ridwan Sau: Julei Rikau)

Nilai budaya Pacce atau Iba tergambar pada lagu Kakde Kapang Nasuruga yaitu pada kalimat pacceku ri sukku lompoa dan kata kamasea yang 
mewakili perasaan iba hati tersebut. Perasaan pacce yang dimaksud dalam lagu ini adalah perasaan iba terhadap diri sendiri karena merasa miskin, merasa tidak tampan, dan merasa hina dari segi silsilah keturunan.

Demikian pula pada lagu Larokong Tojengma Kapang yaitu pada kalimat simpung rera susa loko pacce nyawaku dan kalimat tanu itung pacceku. Kedua kalimat tersebut menggambarkan perasaan iba dan sedih hati karena seseorang.

Pada lagu Tea Tonja bait pertama terdapat kalimat pacce tojengngi paeng yang berarti sungguh sedih dan iba rasanya hatiku, mewakili hati seseorang yang sangat sedih dan baru merasakan sakit setelah mengalami suatu peristiwa dengan seseorang.

4. Nilai Budaya Panngalik 'perasaan hormat'

Nilai Panngalik atau Anngalik dapat dilihat pada lirik-lirik lagu berikut:

I Kattemi Antu

Kakde kapang bayak-bayarang

Bateta ngai ri nakke

Silino akjari doek sayang

Talaganna rekenganna

Kakde nania lani somba

Pantarang Alla Taala

Ikatte kattemi antu anrong

Anrong tu allassukangku

Kontu jamarro panngainta

Bulaeng erang nyawata

Apamo anjo takatte sabak

Niakku empo surug

(Album Ke-3 Ridwan Sau: Jojama Nakke)

Budaya panngalik dalam masyarakat

Makassar dianut sangat ketat. Budaya panngalik atau perasaan hormat ini biasa juga disinonimkan dengan kata sirik-sirik atau malu-malu terhadap sesuatu. Relevansinya terhadap lirik lagu I Kattemi Antu di atas dapat dilihat pada lirik lagu secara keseluruhan yaitu perasaan hormat yang sangat besar pada orang tua yang telah melahirkan seseorang ke dunia ini.

Pada kalimat bait kedua lagu tersebut sebagai berikut:

kakde nania lani somba pantarang Alla Taala Ikatte kattemi antu anrong, anrong tu allassukangku

Terjemahannya:

Andaikan ada yang pantas disembah selain Tuhan Allah Taala maka dikaulah itu ibuku ibu yang melahirkanku.

5. Nilai Budaya Panngadakkang 'Adat Istiadat'

Nilai panngadakkang atau adat istiadat masih terlihat mendominasi masyarakat Makassar. Di kota Makassar sangat menganut kepercayaan yang dipengaruhi oleh adat istiadat tersebut.

Nilai panngadakkang ini tergambar pada keseluruhan lirik lagu Jojama Nakke berikut ini yang menggambarkan seseorang yang sudah bekerja dan berusaha keras untuk mencari uang demi gengsi untuk melamar kekasihnya dengan uang lamaran yang banyak. Namun karena belum mencukupi sehingga proses lamaran tidak bisa terjadi.

Adat tersebut banyak terjadi di Makassar sehingga banyak perempuan memilih menjadi perawan tua daripada menikah dengan 'uang naik' atau uang lamaran seadanya.

Jojama Nakke

Mingka langapaja anne andile

Sanna tommi bateku akkareso

Tenamo allo tenamo banngi kureso

Natena nacini mata pila pacceja kusakring

Pakmaling-maling sangkammaku mami

Panngainku teami ni paui

Mingka apamo ka tena doek andile

Sirikmako antu kau..jojama nakke

Adidi kodong...pakrisikna nyawaku

Eroka bunting nataena doekku

Punna paeng lagesara panrannuangnu 
Boyamako mange ri maraengang, kodong

Gassingka nakke ( latuli nutayang $2 x$ )

Darako sallang $2 x$....ammantangko lolo bangko

Gassingka nakke $2 x \ldots$ tuli nutayang andile

Darako sallang kamase, ammantangko galang santa

(Album ke-3 Ridwan Sau: Jojama Nakke)

Naloko Nakku

Kuempo-empoangminne

Kutinro-tinroang tommi

Aule...kupila kamma

Lapanra naloko nakku

Apamo na passabaki

Kaupa niak ku tekne

Laji nutakucini

Lussa tena pamangeang

Barak nania anjo anging

Akkulle mangerang nakku

Kusuro pabattu tonji

Nakku takarapikangku

(Album ke-3 Ridwan Sau: Jojama

Apamo Anne

Rampemama golla

Kurampeko kaluku

Lontamo anne tassirurungang

(Album ke-3 Ridwan Sau: Jojama Nakke)

Nilai budaya panngadakkang ini juga tergambar pada keseluruhan lagu Naloko Nakku yang menceritakan seseorang yang sangat merindukan kekasihnya yang jauh. Perasaan rindu sangat besar dan menyiksa bahkan membuat sakit dan menderita baginya bila tidak dituruti.

Hal demikian biasa terjadi pada masyarakat Makassar yang berniat menjaga pasangannya sehingga menggunakan mantramantra untuk mengikat sang suami atau kekasihnya dan kekasih atau suaminya tidak bisa melupakannya dan bahkan tidak bisa jauh darinya.

Pada lirik lagu Apamo Anne terdapat sebuah petuah adat yang masih dianut sampai sekarang yaitu pada bait terakhir yaitu:

rampemama golla kurampeko kaluku lontamo anne tassirurungang

Terjemahannya:

Ingatlah aku gula, kuingat kamu kelapa agar kita selalu bersama.

Petuah adat ini sering mengingatkan masyarakat Makassar bahwa gula bila dan kelapa sangat enak rasanya bila digabungkan keduanya menjadi olahan kue. Gula yang manis menandakan sebuah kehidupan diharapkan bahagia ditambahkan dengan kelapa yang nikmat menjadi perpaduan kesempurnaan kebahagiaan.

Petuah adat ini sering digunakan masyarakat Makassar pada saat akan berpisah yang berharap setelah perpisahan itu akan terus teringat kebaikan yang dilakukannya.

6. Nilai Budaya Agama

Nilai agama yang dianut oleh masyarakat Kota Makassar adalah sebuah simbol yang digunakan untuk konsep Tuhan. Hal ini tergambar pula pada lirik lagu Pakngurangi dan Sarengku berikut ini: Panngukrangi

O...karaengku batara tunggala ri takserea Tojengngi kalannyikanta karaeng Tojengngi kasekreangta karaeng Manna nasangka rupa

Kasarak nacini mata

Itung sai ri nyawata

Keresaki lakamma

Anne lino bori lasangga

Tallasatta la lembai ri ahera

Sarengku

Rotasa anne nyawaku

Anjappai tallasakku

Sinoma anne tani toa bija-bija

Kuerangmi pakrisikku tuli anrai kalau

Abboya dalle kuentengan tallasakku

Allo banngi turung songokku

Anjappa timboro wara

Nakumminasa sarengku masunggua

O.... karaengku batara 
Sareangma singaraknu

Sollanna nia kukanyame mateknea

(Sumber: Album 1 Ridwan Sau, Julei Rikau)

Pada bait pertama lirik lagu Pakngurangi terdapat kalimat O...karaengku batara tunggala ri takserea, tojengngi kalannyikanta karaeng, tojengngi kasekreangta karaeng, manna nasangka rupa, kasarak nacini mata yang terjemahannya adalah Oh Tuhanku, tunggal dan Maha Satu, betul kehadiran Tuhan, betul ke Esaan Tuhan, walau ada banyak yang terlihat dan lebih nyata.

\section{SIMPULAN DAN SARAN}

\section{a. Simpulan}

Berdasarkan hasil penelitian dapat disimpulkan sebagai berikut:

1. Nilai sastra hideonik atau kesenangan dan kebahagiaan terdapat pada lirik lagu Julei Rikau, Tea Tonja, dan I Kattemi Antu. Pada lirik-lirik lagu tersebut banyak mengandung nilai-nilai kesenangan dan kebahagiaan baik itu pertemuan dengan sang kekasih, kekaguman pada kecantikan seseorang, dan kebahagiaan menjalani kehidupan, ungkapan untuk menyatakan kebaikan dan kasih sayang ibu.

2. Nilai sastra artistik mengangkat citra kedaerahan masyarakat Makassar. Nilai artistik juga banyak terdapat pada bentuk kata-kata lirik lagu tersebut yang diakhiri dengan fonem-fonem a, i, u, e, dan o. Kalimat-kalimat yang digunakan juga mengandung nilai artistik yang tinggi karena banyak menggunakan perumpamaan. Seperti tergambar pada lirik lagu Kere Tekneku, dan Tea La Panra Pinruang.

3. Nilai kultural dalam lirik lagu Ridwan Sau banyak dipengaruhi dengan nilai kultural masyarakat Kota Makassar. Nilai kultural dapat dilihat pada lirik lagu Burakne Tonja.

4. Nilai etis atau moral terdapat pada liriklirik lagu Ridwan Sau. Pesan dan nilai moral ingin disampaikan kepada pendengar dan penikmat lagu. Seperti salah satu contoh dalam lirik lagu Harangmi yang mengandung pesan bahwa seseorang yang telah mengalami sakit hati dan keputusasaan pada akhirnya harus mengembalikannya kepada Ilahi sang Pencipta.

\section{b. Saran}

Berdasarkan hasil penelitian dan pembahasan yang diuraikan, terdapat beberapa saran dalam penelitian ini sebagai berikut:

1. Masyarakat Makassar harus lebih banyak mengenal dan memahami kodisi sosial budaya daerah yang ditempatinya. Dengan banyak mengenal dan memahami kondisi budaya daerah akan menumbuhkan rasa kecintaan, pembelaan dan berusaha mempertahankan budaya-budaya daerah yang nantinya dapat memperkaya budaya nasional.

2. Budaya-budaya daerah Makassar yang kini dianggap sudah mulai luntur bahkan hilang hendaknya dilestarikan lagi dan ditanamkan pada anak didik sebagai penanaman karakter dari sifat-sifat yang sangat baik.

3. Hendaknya akan hadir lagi generasi Ridwan Sau Ridwan Sau yang lainnya yang berkarya produktif dan dapat lebih memperkaya khazanah lagu-lagu daerah Makassar.

\section{DAFTAR PUSTAKA}

Ahmad, Amin. 1977. Etika. Jakarta: PT. Bulan Bintang.

Ambo Enre, Fachruddin. 1983. Ritumpanna Welenrennge: Telaah Filologis Sebuah Episode Sastra Bugis Klasik Galigo. Jakarta: Universitas Indonesia.

Amir, 2011. Pengantar Sastra. Bandung: CV Sinar Bandung. 
Ancok, D. 2002. Teknik Penyusunan Skala Pengukur. Yogyakarta: Pusat Studi Kependidikan dan Kebijakan, Universitas Gadjah Mada.

Atmazaki. 1990. Ilmu Sastra Teori dan Terapan. Padang: Angkasa Raya

Azis, Siti Aida. 2011. Etika dan Kepemimpinan dalam Novel-Novel Karya Pramoedya Ananta Toer. Disertasi. Surabaya: Universitas Negeri Surabaya Program Pascasarjana Program Pendidikan Bahasa dan Sastra Indonesia.

Bakker, J. W. M. 1984. Filsafat Kebudayaan. Yogyakarta: Kanisius.

Bantang, Sirajuddin. 2008. Sastra Makassar. Makassar: Pustaka Refleksi.

Basri. 2005. Ilmu Pengetahuan Sosial Sulawesi Selatan untuk kelas IV SD. Klaten: Cempaka Putih

Budiyanto. 2002. Membaca Sastra (Pengantar Memahami Sastra untuk Perguruan Tinggi). Magelang: Indonesiatera.

Danandjaja, James. 2002. Folklor Indonesia. Jakarta: Depdikbud.

Djajasudarma, Fatimah G. 2006. Ancangan Metode Penelitian dan Kajian Sastra. Bandung: Refika Aditama.

Djamaries, dkk.1996. Nilai-Nilai dalam Kesusasteraan. Padang: Angkasa Raya.

Endraswara, Suwardi. 2003. Metodologi Penelitian Sastra. Yogyakarta: Pustaka Pelajar

Faruk. 1994. Pengantar Sosiologi Sastra dari Strukturalisme Genetik sampai
Post Modernisme. Yogyakarta: Pustaka Pelajar.

Fitriana, Irna. 2011. Keefektifan Teori Strukturalisme Genetik dalam Menganalisis Cerpen Mahasiswa Semester VI Jurusan Pendidikan Bahasa dan Sastra Indonesia. Skripsi.Sulawesi Selatan: STKIP Muhammadiyah Bone.

Goldman, Lucien. 1977. Toward A. Sociology of the Karya Sastra. Tavisiock Publications.

Hamid, Abu. 2005. Budaya Sirik Na Pesse Sulawesi Selatan . Makassar: Refleksi.

Hamka., Yakub. 1997. Etika Islam. Bandung: Dipenogoro.

Hasanuddin. 1981. Membaca dan Menilai Sajak. Pengantar dan Interprestasi. Bandung: Penertbit Angkasa.

Jabrohim. 1994. Teori Penelitian Sastra. Yogyakarta: Masyarakat Poetica Indonesia IKIP Muhammadiyah Yogyakarta.

Jarkasi. 2011. Nilai Budaya Siri' sebagai Motivasi untuk Meningkatkan Mutu Pendidikan di Sulawesi Selatan. Ujung Pandang: Panitia Penyelenggara Seminar.

Junaedi, Moha. 1992. Apresiasi Sastra Indonesia. Ujung Pandang: CV. Putra Maspul.

Kaelan. 2002. Filsafat Bahasa (Realitas Bahasa, Logika Bahasa Hermeneutika dan Postmodernisme. Yogyakarta: Paradigma 
Kamal Pasha, Musthafa dkk. 2000. Ilmu Budaya Dasar. Yogyakarta: Citra Karsa Mandiri.

Lathief, Halilintar. 2009. Royong Tradisi Makassar yang Ditinggalkan. Makassar: Padat Daya.

Luxemburg, Jan Van dkk. 1989. Pengantar Ilmu Sastra. Jakarta: Gramedia.

Mahmud, A. Hasan. 1997. Silasa: Setetes Embun di Tanah Gersang. Makassar: YKSST.

Mangemba, HD. 1956. Kenallah Sulawesi Selatan. Jakarta: Timun Mas.

Mangunwijaya, Y. B. 1988. Sastra dan Religiositas. Yogyakarta: Kanisius.

Maryani N, Sri. 2010. Analisis Strukturalisme Genetik Novel Ketika Cinta Bertasbih.

Mattulada. 1982. Menyusuri Jejak Kehadiran Makassar dalam Sejarah (1510- 1700). Makassar: Bhakti Baru- Berita Utama.

Muhammad, Soelaeman. 2005. Ilmu Budaya Dasar. Bandung: PT Eresco

Nurgiyantoro, Burhan. 2009. Teori Pengkajian Fiksi. Yogyakarta: Gadjah Mada University Press.

Piaget, Jean. 1995. Strukturalisme. Terjemahan. Jakarta: Yayasan Obor Indonesia.

Pradopo,Rahmat Djoko.1987. Pengkajian Puisi: Analisis Strata Norma dan Analisis Struktural dan Semiotik.Yogyakarta:Gadjahmada University Press.

Rahim, Abd. Rahman. 1985. Nilai-nilai Utama Kebudayaan Bugis. Makassar:
Lembaga Penerbitan Uneversitas Hasanuddin.

Ratna, Nyoman Kutha. 2009. Teori, Metode, dan Teknik Penelitian Sastra. Yogyakarta: Pustaka Pelajar.

Satoto, Sudiro. 1993. Metodologi Penelitian Sastra. Surakarta: UNS Press.

Selden, Raman. 1994. A Readers Guide To Contemporary Literary Theory. Britain: The Harvester Press Limited.

Semi, Atar. 1988. Anatomi Sastra. Padang: Angkasa Raya.

Semi, Atar. 2011. Rancangan Pengajaran Bahasa dan Sastra Indonesia. Yogyakarta: Pustaka Pelajar

Setyowati. 1989. Telaah Sastra Indonesia. Bandung: Angkasa.

Sikki, M dkk. 1991. Nilai-Nilai Budaya dalam Sastra Daerah Sulawesi Selatan. Jakarta: Pusat Pembinaan dan Pengembangan Bahasa.

Simorangkir, O. P. 1987. Etika Jabatan. Jakarta: Aksara Persada Press.

Soeratno.1994. Gusti Ora Sare: 65 Mutiara Nilai Kearifan Budaya Jawa. Yogyakarta: Adiwacana.

Spradley, James P. 1990. Participant Observation. New York: Holt Rinehard and Winston.

Sudarsono. 2001. Ilmu Filsafat Suatu Pengantar. Jakarta: Rineka Cipta.

Sukatman. 1992. Nilai-nilai Kultural Edukatif dalam Peribahasa Indonesia. Tesis. S2 yang tidak 
dipublikasikan. Malang: IKIP Program Pasca Sarjana.

Sumardjo, Jakob. 1984. Budaya-Budaya Indonesia. Bandung: Citra Aditya Bakti.

Suparlan, Y. B. 1983. Kamus Istilah Kesejahteraan Sosial. Yogyakarta: Pusat Pembinaan dan Pengembangan Bahasa dan Budaya

Suwondo, Tirto. 1994. Studi Sastra. Beberapa Alternatif . Yogyakarta: Hanindita Graha Widya.

Syuhadak. 2010. Nilai-Nilai Kultural Edukatif Dalam "Basanan” Using Banyuwangi Dan Pemanfaatannya Sebagai Alternatif Materi Pembelajaran Apresiasi Sastra Di Sekolah . Skripsi tidak dipublikasikan. FKIP PBSI. Universitas Jember.

Tafsir, Ahmad. 1999. Filsafat Umum: Akal dan Hati Semenjak Thales sampai James. Jakarta: Remaja Rosda Karya.

Teeuw, A. 1984. Sastra dan Ilmu Sastra. Jakarta: Pustaka Jaya.

Wahid, Sugirah. 2007. Manusia Makassar. Makassar: Pustaka Refleksi.

Wahid, S. 1988. Metafora Bahasa Makassar. Disertasi. Ujung Pandang: FPS Unhas.

Wahyuningtyas, Sri .2011. Sastra: Teori dan Implementasi. Surakarta: Yuma Pustaka.

Wellek, Rene dan Austin Warren. 1989. Theory of Literature. Jakarta: Gramedia.

Yasin Limpo, Syahrul. 1995. Profil Sejarah, Budaya, dan Pariwisata Gowa.
Gowa Sulawesi Selatan: Pemerintah Daerah Tk. II Gowa dan Yayasan Eksponen 1966 Gowa.,

Yunus. 1981. Penelitian-Penelitian Sastra. Surakarta: UNS Press.

Zainal Abidin, Andi. 1999. Capita Selecta Kebudayaan Sulawesi Selatan. Makassar: Hasanuddin University Press Ujung Pandang.

http://www.farham-bjm.web.id/2011/09/ pengertian -sastra- dan cerpen-serta. html. Diakses pada tanggal 28 April 2012.

http://griyawardani,wordpres.com/2011/05/2 4/nilai-nilai-dalam-sastra/. Diakses pada tanggal 28 April 2012. 